\title{
Inadequate Weight Gain According to the Institute of Medicine 2009 Guidelines in Women with Gestational Diabetes: Frequency, Clinical Predictors, and the Association with Pregnancy Outcomes
}

\author{
Xinglei Xie ${ }^{1}{ }^{1}$, Jiaming Liu ${ }^{1}{ }^{1}$, Isabel Pujol ${ }^{2}$, Alicia López ${ }^{2}$, María José Martínez ${ }^{2}$, \\ Apolonia García-Patterson ${ }^{3}$, Juan M. Adelantado ${ }^{4}$, Gemma Ginovart ${ }^{5}$ and $\operatorname{Rosa}_{\text {Corcoy }}{ }^{1,2,3,6, *(\mathbb{D})}$ \\ 1 Departament de Medicina, Universitat Autònoma de Barcelona, Bellaterra, 08193 Barcelona, Spain; \\ xxienglei@santpau.cat (X.X.); ljiaming@santpau.cat (J.L.) \\ 2 Servei d'Endocrinologia i Nutrició, Hospital de la Santa Creu i Sant Pau, 08041 Barcelona, Spain; \\ ipujol@santpau.cat (I.P.); alopezar@santpau.cat (A.L.); mmartinezr@santpau.cat (M.J.M.) \\ 3 Institut de Recerca, Hospital de la Santa Creu i Sant Pau, 08041 Barcelona, Spain; 31178agp@comb.cat \\ 4 Servei de Ginecologia i Obstetricia, Hospital de la Santa Creu i Sant Pau, 08041 Barcelona, Spain; \\ adelantadojm@gmail.com \\ 5 Servei de Pediatria, Hospital de la Santa Creu i Sant Pau, 08041 Barcelona, Spain; \\ gginovart.germanstrias@gencat.cat \\ 6 CIBER-BBN, 28029 Madrid, Spain \\ * Correspondence: rcorcoy@santpau.cat; Tel.: +349-3556-5661
}

Received: 21 September 2020; Accepted: 14 October 2020; Published: 18 October 2020

\begin{abstract}
Background: In the care of women with gestational diabetes mellitus (GDM), more attention is put on glycemic control than in factors such as gestational weight gain (GWG). We aimed to evaluate the rate of inadequate GWG in women with GDM, its clinical predictors and the association with pregnancy outcomes. Methods: Cohort retrospective analysis. Outcome variables: GWG according to Institute of Medicine 2009 and 18 pregnancy outcomes. Clinical characteristics were considered both as GWG predictors and as covariates in outcome prediction. Statistics: descriptive, multinomial and logistic regression. Results: We assessed 2842 women diagnosed with GDM in the 1985-2011 period. GWG was insufficient (iGWG) in 50.3\%, adequate in $31.6 \%$ and excessive (eGWG) in $18.1 \%$; length of follow-up for GDM was positively associated with iGWG. Overall pregnancy outcomes were satisfactory. GWG was associated with pregnancy-induced hypertension, preeclampsia, cesarean delivery and birthweight-related outcomes. Essentially, the direction of the association was towards a higher risk with eGWG and lower risk with iGWG (i.e., with Cesarean delivery and excessive growth). Conclusions: In this cohort of women with GDM, inadequate GWG was very common at the expense of iGWG. The associations with pregnancy outcomes were mainly towards a higher risk with eGWG and lower risk with iGWG.
\end{abstract}

Keywords: gestational diabetes mellitus; Institute of Medicine; weight gain; length of follow-up; pregnancy outcome

\section{Introduction}

Gestational diabetes mellitus (GDM) entails risks for the mother and the newborn, both at short and long-term [1,2]. Among others, it increases the risk of preeclampsia, caesarean section, and future type 2 diabetes for the mother [3,4] and for the baby it increases the risk of diabetic fetopathy at short term and metabolic syndrome at long term [5]. In turn, high pre-pregnancy body mass index (BMI) is associated with higher risks of gestational hypertension and GDM [6] as well as with 
unfavorable pregnancy outcomes $[7,8]$. Likewise, gestational weight gain (GWG) is related to adverse pregnancy outcomes. In the general obstetric population, excessive GWG (eGWG) is associated with a higher risk of hypertensive disorders of pregnancy, GDM, caesarean section, postpartum weight retention, large for gestational age (LGA) and macrosomic newborns [9,10]. In turn, insufficient GWG (iGWG) is associated with a higher risk of preterm birth and small for gestational babies (SGA) [11-13]. In 2009, the Institute of Medicine (IOM) provided specific guidelines regarding the recommended GWG according to BMI categories to optimize pregnancy outcome [14].

In diabetic pregnancy, inadequate GWG is prevalent both in women with GDM and those with pregestational diabetes $[13,15,16]$ and has also been related to perinatal outcome. In a meta-analysis on GWG and pregnancy outcomes in women with GDM, eGWG was associated with a higher frequency of pregnancy-induced hypertension (PIH), cesarean delivery, LGA newborns and macrosomia in relation to an adequate GWG (aGWG) whereas iGWG was associated with a lower risk of LGA and macrosomia. The risk of LGA was $\simeq$ double with $\mathrm{eGWG}$ and $\simeq 0.70$ with iGWG [13]. Articles addressing this point in our background are limited [17-19] and, therefore, we aimed to evaluate the frequency of inadequate GWG in women with GDM attended in our center, its clinical predictors and the association with pregnancy outcomes.

\section{Materials and Methods}

\subsection{Study Design}

The present study is a retrospective analysis of data collected prospectively in the database of the Endocrinology and Pregnancy Clinic at Hospital de la Santa Creu i Sant Pau. All patients provided written informed consent for inclusion in the database and the study has been approved by the Ethics Committee of the Institut de Recerca de l'Hospital de la Santa Creu i Sant Pau and has been performed in accordance with the Declaration of Helsinki. We evaluated patients with GDM who were attended in our center between 1 January 1985 and 31 December 2011. Throughout this period, GDM has been diagnosed after National Diabetes Data Group Criteria, continued after an evaluation of the potential impact of Carpenter and Coustan criteria [20,21]. Treatment approach has essentially kept constant: normocaloric diet (usually ranging from 1800 to 2200 calories per day), self-monitoring of ketonuria (aiming at its absence) and of blood glucose (aiming at fasting/preprandial $<90 \mathrm{mg} / \mathrm{dL}$ and $1 \mathrm{~h}$ postprandial $<120 \mathrm{mg} / \mathrm{dL}$ unless fetal growth is $<10$ th centile).

\subsection{Variables Collected}

Adequacy of GWG was categorized according to IOM 2009 into insufficient, adequate (reference category) and excessive weight gain. GWG was calculated as the difference between the last weight available during pregnancy and prepregnancy (see Appendix A Table A1). As potential independent variables, we have considered maternal ethnicity (non-Caucasian), age at the beginning of pregnancy, maternal anthropometry (height and prepregnancy BMI category), family history of diabetes, prior history of abnormal glucose tolerance (GDM/impaired fasting glucose/glucose intolerance), prior pregnancy, unfavorable obstetric history (macrosomia, pregnancy-induced hypertension, recurrent miscarriage, non-syndromic malformation, unexplained fetal death, polyhydramnios, pyelonephritis), multiple pregnancy, smoking habit during pregnancy (non-smoker at the beginning of pregnancy, quitter or active smoker during pregnancy), characteristics of GDM diagnosis (gestational age at diagnosis, season, glycemic values, number of abnormal glucose values, autoimmunity against beta cell), gestational age at delivery and length of specific follow-up at the Diabetes and Pregnancy Clinic.

We addressed 4 maternal and 14 neonatal outcomes, defined as follows: PIH (blood pressure $\geq$ $140 / 90 \mathrm{mmHg}, \times 2$ times separated $\geq 6 \mathrm{~h}$, starting at a gestational age $\geq 20$ weeks or worsening chronic hypertension), preeclampsia ( $\mathrm{PIH}$, accompanied by proteinuria), insulin treatment, cesarean delivery (total), fetal scalp blood $\mathrm{pH}<7.25$ [22], preterm birth (defined as a gestational age at birth less than 37 complete weeks), Apgar $5 \mathrm{~min}<7$ [23], arterial $\mathrm{pH}<7.10$ [24], significant obstetric trauma, 
LGA newborn (birth weight $>90 \%$ centile for the same gestational age and sex [25], macrosomia (defined as a birth weight $\geq 4000 \mathrm{~g}$ ), small for gestational age (SGA) newborn (birth weight $<10 \%$ centile for the same gestational age and sex) [25], neonatal hypoglycemia (Cornblath criteria applied to capillary blood) [26], neonatal jaundice requiring treatment [27], neonatal respiratory requiring treatment distress [28], neonatal hypocalcemia [29], polycythemia [30] and perinatal mortality (intrauterine or until 28 days postpartum taking into account fetal viability: before 1991, <28 completed weeks; 1991-1994, $<26$ completed weeks; 1995-1999, <24 completed weeks and from 2000 onwards, $<23$ completed weeks). As potential independent variables for pregnancy outcomes in addition to GWG, we considered the following characteristics: maternal ethnicity, age at the beginning of pregnancy, maternal anthropometry (height and pre-pregnancy BMI category), prior pregnancy, multiple pregnancy, smoking habit during pregnancy (non-smoker at the beginning of pregnancy, quitter or active smoker during pregnancy), characteristics of GDM diagnosis (gestational age at diagnosis, glycemic values), delay between diagnosis and initiation of specific follow-up, first $\mathrm{HbA} 1 \mathrm{c}$ after diagnosis, average $\mathrm{HbA} 1 \mathrm{c}$ in the third trimester) and fetal sex. In multiple pregnancies, a variable of concordant fetal sex was computed to be used in the analysis of fetal outcomes; for maternal outcomes, the sex of the fetus with higher risk was used. The variables above were used for the adjusted analysis of all outcomes with the exception of average $\mathrm{HbA} 1 \mathrm{c}$ in the third trimester that was excluded for the adjusted analysis of insulin treatment. Over the years, different methods have been used to determine glycated hemoglobin. Currently, it is measured in whole blood using cation exchange HPLC (Variant II Turbo HbA1c, Bio-Rad Laboratories, Hercules, CA, USA). The results obtained with the different methods have been collected as SD around the mean and translated into values referred to DCCT.

\subsection{Statistical Analysis}

Statistical analyses were performed using the SPSS version 26.0 software package. Descriptive results are expressed as mean and standard deviation (SD) or P50 (P25-P75) for continuous variables according to their normal or non-normal distribution. Categorical variables are expressed as percentages. We compared characteristics between the GWG categories using a Chi-square test or a Kruskal-Wallis test as appropriate (the variable being categorical or quantitative, non-normally distributed). Imputations were not used to deal with missing data.

To address the clinical characteristics associated with GWG according to IOM, we performed a multivariate multinomial logistic regression analysis with a forward method using as dependent variable weight gain according to IOM (reference category: aGWG) and using as potential predictors the variables with a $p$ value $<0.100$ in the bivariate analysis.

To determine the association of GWG according to IOM with pregnancy outcomes, we performed a logistic regression analysis (forward method) using aGWG as the reference category. Results were expressed as non-adjusted odds ratios (OR) and adjusted odds ratios (aOR) and 95\% confidence intervals (95\% CI). For the adjusted analysis, we fed in the model all the potential predictors indicated above.

A $p$ value $<0.05$ was used as the cut-off for significance in the multivariate analysis. All $p$ values were two-sided.

\section{Results}

A total of 2842 pregnant women with GDM were attended during the period and information regarding GWG according to IOM and potential predictors was available in 2700 (2594 with singleton pregnancies, 106 with multiple pregnancies, $95.0 \%$ of the target population), with analyses being performed in this group. A total of 2818 babies were born from these mothers (2594 from singleton, 224 from multiple pregnancies). Figure 1 displays the flowchart of patient inclusion. Results on preeclampsia are limited to the last period when information on proteinuria was included in the database $(\mathrm{N}=377)$.

Table 1 shows the characteristics of these women. Main characteristics are as follows: most women had a normal prepregnancy BMI, $62.3 \%$ women had been pregnant before, GDM was diagnosed 
at a gestational age of 29 weeks and length of specific follow-up was 7 weeks. Median GWG was $10.2 \mathrm{~kg}$. The distribution of GWG according to IOM was: $50.3 \%$ insufficient, $31.6 \%$ adequate and $18.1 \%$ excessive (Figure 2). In the bivariate analysis, 13 out of the 20 characteristics considered as potential independent variables had a $p$ value $<0.100$ among the three groups of women. Among these variables, prepregnancy overweight/obesity and smoking habit at the beginning of pregnancy (women quitting smoking/active smokers during pregnancy) increased throughout the categories of GWG. The length of follow-up for GDM was negatively associated with GWG (Table 1, Appendix B, Figure A1).

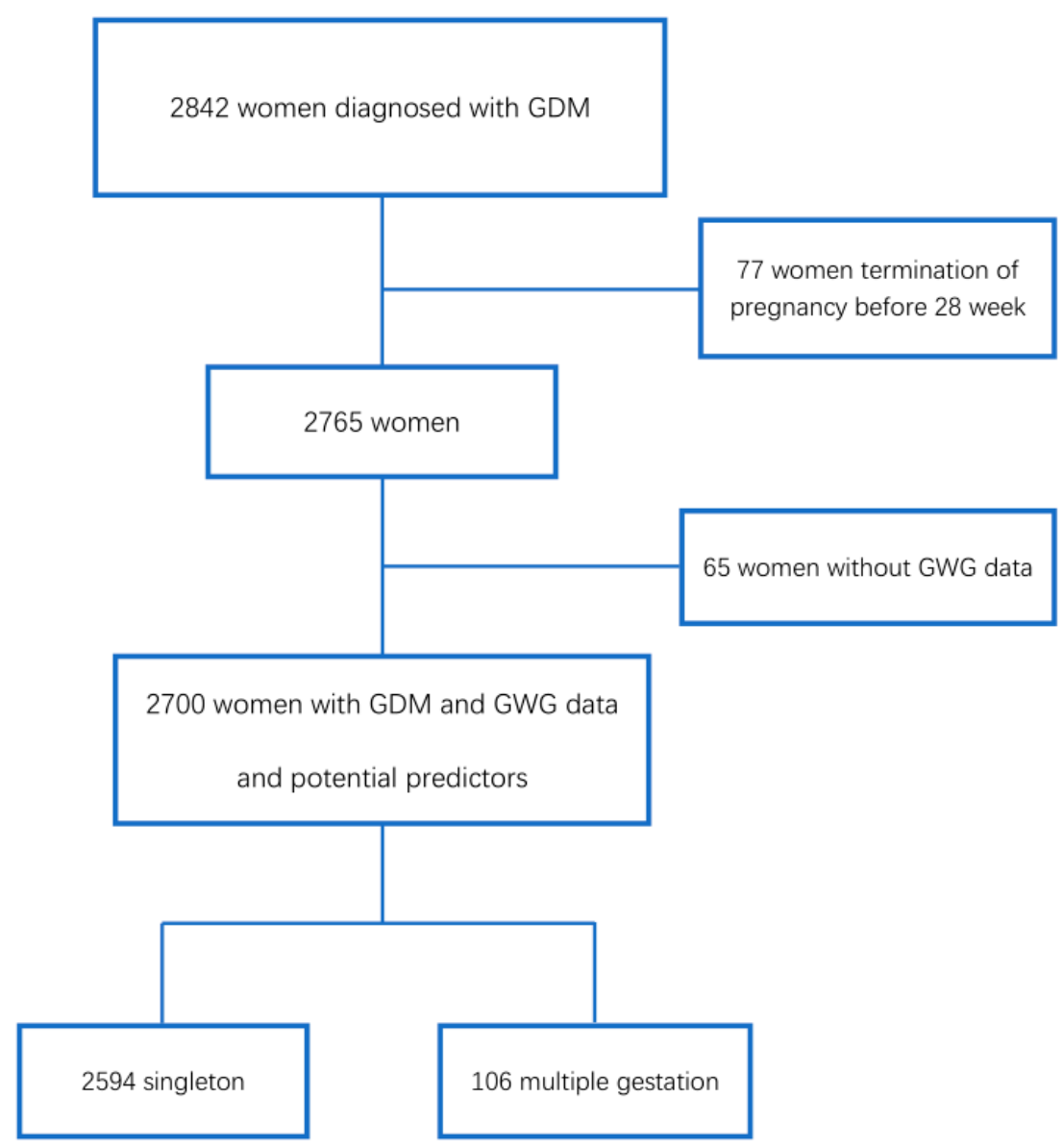

Figure 1. Flowchart of inclusion of patients in the study. GDM: Gestation Diabetes Mellitus. GWG: Gestational Weight Gain.

Results of the multinomial logistic regression are presented in Table 2 with seven characteristics being significantly associated with categories of GWG after IOM: non-Caucasian ethnicity, height, prepregnancy BMI category, unfavorable obstetric history, smoking habit, gestational age at delivery and length of follow-up.

For iGWG, independent variables were maternal height, prepregnancy overweight/obesity, unfavourable obstetric history, smoking habit (active smoker and quitter during pregnancy), gestational age at delivery and length of follow-up, all of them negatively associated with the exception of length of follow-up (OR 1.035 per week; 95\% CI 1.018-1.052). For eGWG, independent variables were non-Caucasian ethnicity, prepregnancy overweight/obesityand smoking habit (active smoker and quitter during pregnancy), all of them positively associated with eGWG. The length of follow-up was negatively associated with borderline significance.

According to the recommendations of Institute of Medicine 2009, approximately 50\% of women with gestational diabetes had insufficient weight gain during pregnancy, $18 \%$ excessive weight gain and $32 \%$ adequate weight gain. 
Table 1. Characteristics of the study participants, both overall and according to category of weight gain after Institute of Medicine 2009

\begin{tabular}{|c|c|c|c|c|c|}
\hline \multirow{2}{*}{ Characteristic } & \multicolumn{4}{|c|}{$\%$ or P50 $(\mathrm{P} 25, \mathrm{P} 75)$ in Each Weight Gain Category } & \multirow{2}{*}{$p$ within IOM Categories * } \\
\hline & Overall & Weight Gain < IOM & Weight Gain within IOM & Weight Gain > IOM & \\
\hline Non-Caucasian ethnicity (\%) & 5.5 & 4.4 & 3.8 & 11.3 & $<0.001$ \\
\hline Age (years) & $33.0(29.0 ; 36.0)$ & $33.0(29.0 ; 36.0)$ & $33.0(30.0 ; 36.0)$ & $33.0(29.0 ; 36.0)$ & 0.694 \\
\hline Height $(\mathrm{cm})$ & $160(155 ; 164)$ & $159(155 ; 163)$ & $160(156 ; 164)$ & $160(156 ; 164)$ & 0.002 \\
\hline \multicolumn{6}{|l|}{ Prepregnancy BMI category (\%) } \\
\hline - Underweight & 2.6 & 2.7 & 3.4 & 1.0 & \multirow{4}{*}{$<0.001$} \\
\hline - $\quad$ Normal weight & 63.1 & 77.9 & 58.5 & 30.1 & \\
\hline - Overweight & 23.5 & 12.3 & 28.8 & 45.5 & \\
\hline - $\quad$ Obesity & 10.7 & 7.1 & $\begin{array}{c}20.0 \\
9.3\end{array}$ & 23.4 & \\
\hline Family history of diabetes (\%) & 56.4 & 54.4 & 57.7 & 59.8 & 0.083 \\
\hline $\begin{array}{l}\text { Prior history of abnormal glucose } \\
\text { tolerance/gestational diabetes mellitus (\%) }\end{array}$ & 13.7 & 13.5 & 13.5 & 14.7 & 0.783 \\
\hline Prior pregnancy $(\%)$ & 62.3 & 60.0 & 64.6 & 65.0 & 0.041 \\
\hline Unfavorable obstetric history (\%) & 12.8 & 9.3 & 15.3 & 18.4 & $<0.001$ \\
\hline Multiple pregnancy (\%) & 3.9 & 5.7 & 2.3 & $1 . .6$ & $<0.001$ \\
\hline \multicolumn{6}{|l|}{ Smoking habit during pregnancy } \\
\hline - $\quad$ quitter $(\%)$ & 11.5 & 9.5 & 12.2 & 15.8 & \multirow[t]{2}{*}{$<0.001$} \\
\hline - $\quad$ active smokers (\%) & 23.4 & 20.8 & 24.7 & 28.2 & \\
\hline \multicolumn{6}{|l|}{ Season at gestational diabetes mellitus diagnosis } \\
\hline - $\quad$ summer & 31.0 & & 30.7 & 32.4 & \multirow{3}{*}{0.681} \\
\hline - autumn & 25.2 & 24.6 & 26.7 & 24.2 & \\
\hline - $\quad$ winter & 19.3 & 20.1 & 17.6 & 20.1 & \\
\hline $\begin{array}{l}\text { Gestational age at diagnosis of gestational } \\
\text { diabetes mellitus (weeks) }\end{array}$ & $29(26 ; 33)$ & $29(25 ; 33)$ & $30(26 ; 33)$ & $29(26 ; 34)$ & 0.008 \\
\hline \multicolumn{6}{|l|}{ Glycemic values $(\mathrm{mmol} / \mathrm{L})$ at diagnosis } \\
\hline - Glucose $0 \mathrm{~h}$ & $4.7(4.3 ; 5.1)$ & $4.6(4.3 ; 5.0)$ & $4.7(4.31 ; 5.1)$ & $4.9(4.5 ; 5.4)$ & $<0.001$ \\
\hline - $\quad$ Glucose $1 \mathrm{~h}$ & $11.6(10.9 ; 12.5)$ & $11.6(10.9 ; 12.5)$ & $11.6(10.8 ; 12.4)$ & $11.5(10.9 ; 12.6)$ & 0.562 \\
\hline - $\quad$ Glucose $2 \mathrm{~h}$ & $10.2(9.6 ; 11.1)$ & $10.2(9.6 ; 11.1)$ & $10.2(9.6 ; 11.1)$ & $10.2(9.5 ; 11.1)$ & 0.183 \\
\hline - $\quad$ Glucose $3 \mathrm{~h}$ & $7.8(6.6 ; 8.8)$ & $7.9(6.8 ; 8.8)$ & $7.9(6.6 ; 8.8)$ & $7.5(6.1 ; 8.7)$ & 0.002 \\
\hline Number of abnormal glucose values & $2(2 ; 3)$ & $2(2 ; 3)$ & $2(2 ; 3)$ & $2(2 ; 3)$ & 0.594 \\
\hline Autoimmunity against beta cells (\%) & 9.2 & 9.0 & 9.4 & 9.6 & 0.904 \\
\hline Gestational age at delivery (weeks) & $39(38 ; 40)$ & $39(38 ; 40)$ & $39(38 ; 40)$ & $39(38 ; 40)$ & $<0.001$ \\
\hline Length of follow-up (weeks) & $7(3 ; 11)$ & $7(4 ; 11)$ & $7(4 ; 10)$ & $6(3 ; 10)$ & 0.032 \\
\hline Weight gain $(\mathrm{kg})$ & $10.2(7.7 ; 13.0)$ & $8.2(5.7 ; 10.0)$ & $12.2(9.5 ; 13.9)$ & $16.0(13.0 ; 18.2)$ & $<0.001$ \\
\hline
\end{tabular}

IOM: Institute of Medicine; BMI: body mass index; ${ }^{*}$ Variables different from weight gain with a $p$ value $<0.100$ after bivariate multinomial regression analysis are displayed in bold characters and used in the multivariate multinomial logistic regression analysis. 
Table 2. Independent variables for insufficient or excessive gestational weight gain according to IOM 2009 (multinomial multivariate logistic regression analysis).

\begin{tabular}{|c|c|c|c|c|c|c|c|}
\hline & \multicolumn{3}{|c|}{ Insufficient Weight Gain } & \multirow[b]{2}{*}{ Overall $p$} & \multicolumn{3}{|c|}{ Excessive Weight Gain } \\
\hline & OR & $p$ & $95 \%$ CI & & OR & $p$ & $95 \%$ CI \\
\hline $\begin{array}{l}\text { Non-Caucasian ethnicity (yes) } \\
\text { Height }(\mathrm{cm}) \\
\text { Prepregnancy BMI category }\end{array}$ & $\begin{array}{l}1.182 \\
0.979\end{array}$ & $\begin{array}{l}0.500 \\
\mathbf{0 . 0 0 8}\end{array}$ & $\begin{array}{l}0.727-1.922 \\
\mathbf{0 . 9 6 3 - 0 . 9 9 4}\end{array}$ & $\begin{array}{l}<0.001 \\
0.001\end{array}$ & $\begin{array}{l}3.283 \\
1.020\end{array}$ & $\begin{array}{l}<0.001 \\
0.062\end{array}$ & $\begin{array}{l}\mathbf{1 . 9 8 4 - 5 . 4 3 3} \\
0.999-1.041\end{array}$ \\
\hline $\begin{array}{ll}\text { - } & \text { Underweight } \\
\text { - } & \text { Normal weight } \\
\text { (reference category) } \\
\text { - } & \text { Overweight } \\
\text { - } & \text { Obesity }\end{array}$ & $\begin{array}{c}0.659 \\
1 \\
\mathbf{0 . 3 0 1} \\
\mathbf{0 . 6 0 3}\end{array}$ & $\begin{array}{c}0.137 \\
<0.001 \\
0.005\end{array}$ & $\begin{array}{l}0.381-1.142 \\
0.235-0.387 \\
\mathbf{0 . 4 2 5 - 0 . 8 5 7}\end{array}$ & $<0.001$ & $\begin{array}{l}0.487 \\
1 \\
3.190 \\
5.060\end{array}$ & $\begin{array}{l}0.191 \\
<0.001 \\
<0.001\end{array}$ & $\begin{array}{l}0.165-1.433 \\
\\
2.403-4.234 \\
3.472-7.375\end{array}$ \\
\hline $\begin{array}{l}\text { Unfavorable obstetric history (yes) } \\
\text { Smoking habit }\end{array}$ & 0.520 & $<0.001$ & $0.387-0.700$ & $<0.001$ & 0.865 & 0.399 & $0.618-1.211$ \\
\hline $\begin{array}{ll}\text { - } & \begin{array}{l}\text { Non-smoker } \\
\text { (reference category) }\end{array} \\
\text { - } & \text { Quitter during pregnancy (yes) } \\
\text { - } & \text { Active smoker during } \\
& \text { pregnancy (yes) }\end{array}$ & $\begin{array}{c}1 \\
0.668 \\
0.727\end{array}$ & $\begin{array}{l}0.011 \\
0.007\end{array}$ & $\begin{array}{l}0.490-0.910 \\
0.576-0.918\end{array}$ & $<0.001$ & $\begin{array}{c}1 \\
1.614 \\
1.382\end{array}$ & $\begin{array}{l}0.010 \\
0.030\end{array}$ & $\begin{array}{l}1.121-2.325 \\
1.031-1.852\end{array}$ \\
\hline $\begin{array}{l}\text { Gestational age at delivery (weeks) } \\
\text { Length of follow-up (weeks) }\end{array}$ & $\begin{array}{l}0.855 \\
1.035\end{array}$ & $\begin{array}{l}<0.001 \\
<0.001\end{array}$ & $\begin{array}{l}0.806-0.907 \\
1.018-1.052\end{array}$ & $\begin{array}{l}<0.001 \\
<0.001\end{array}$ & $\begin{array}{l}1.026 \\
0.980\end{array}$ & $\begin{array}{l}0.527 \\
0.066\end{array}$ & $\begin{array}{l}0.947-1.113 \\
0.958-1.001\end{array}$ \\
\hline
\end{tabular}




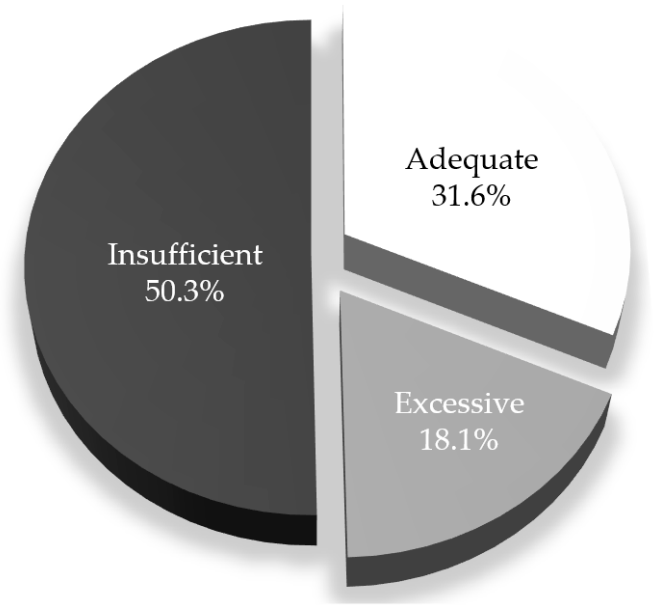

Figure 2. Distribution of gestational weight gain according to Institute of Medicine 2009.

Pregnancy outcomes according to IOM 2009 are presented in Table 3, with significant associations with three maternal (PIH, preeclampsia, cesarean delivery) and eight fetal outcomes (preterm birth, arterial $\mathrm{pH}<7.1$, LGA, macrosomia, SGA, jaundice requiring treatment, respiratory distress requiring treatment and neonatal hypocalcemia).

Table 3. Pregnancy outcomes of women with gestational diabetes mellitus according to gestational weight gain category.

\begin{tabular}{lccccc}
\hline \multicolumn{1}{c}{ Outcome } & \multicolumn{7}{c}{ Prevalence (\%) in Each GWG Category } & \multirow{2}{*}{ Overall $p$} \\
& Overall & iGWG & aGWG & eGWG & \\
\hline Pregnancy-induced hypertension & 5.3 & 3.4 & 5.5 & 10.1 & $<0.001$ \\
Preeclampsia & 2.9 & 1.3 & 1.7 & 6.5 & 0.031 \\
Insulin treatment & 46.8 & 45.4 & 46.5 & 51.4 & 0.068 \\
Cesarean delivery & 24.1 & 19.9 & 23.4 & 36.8 & $<0.001$ \\
Fetal scalp blood pH $<7.25$ & 3.8 & 3.1 & 4.0 & 5.3 & 0.077 \\
Preterm birth & 9.8 & 13.3 & 6.9 & 4.8 & $<0.001$ \\
Apgar at 5 min $<7$ & 0.5 & 0.6 & 0.3 & 0.4 & 0.735 \\
Arterial pH $<7.1$ & 3.8 & 3.5 & 3.1 & 6.0 & 0.035 \\
Obstetric trauma & 2.3 & 2.1 & 2.6 & 2.4 & 0.697 \\
LGA newborn & 11.2 & 6.4 & 10.7 & 26.1 & $<0.001$ \\
Macrosomia ( $\geq$ 4000 g) & 5.7 & 2.4 & 5.7 & 14.9 & $<0.001$ \\
SGA newborn & 9.9 & 11.7 & 9.3 & 5.9 & 0.001 \\
Neonatal hypoglycemia & 2.5 & 2.4 & 2.5 & 2.7 & 0.932 \\
Jaundice requiring treatment & 5.1 & 6.1 & 4.0 & 4.1 & 0.040 \\
Respiratory distress requiring treatment & 3.3 & 4.7 & 1.9 & 2.0 & $<0.001$ \\
Neonatal hypocalcemia & 1.6 & 2.5 & 1.0 & 0.0 & 0.009 \\
Neonatal polycythemia & 1.4 & 1.3 & 1.4 & 1.8 & 0.662 \\
Perinatal mortality & 0.5 & 0.6 & 0.5 & 0.2 & 0.603 \\
\hline
\end{tabular}

GWG (gestational weight gain), iGWG (insufficient gestational weight gain), aGWG (adequate gestational weight gain), eGWG (excessive gestational weight gain), LGA (large-for-gestational age), SGA (small-for-gestational age). A Chi-square test was used for statistical analyses.

Unadjusted and adjusted OR resulting from logistic regression are presented in Table 4 . In the adjusted analysis, GWG according to IOM was significantly associated with PIH, preeclampsia, cesarean delivery, LGA, macrosomia and SGA. With the exception of SGA, eGWG was associated with higher risks and iGWG with lower risks even when for some variables (PIH, preeclampsia and SGA), significance was present for GWG according to IOM but not for individual categories of iGWG and eGWG. Additionally, iGWG was associated with neonatal hypocalcemia (aOR 4.557, 95\% CI 1.037-20.003) even when the global association of GWG did not reach significance (overall $p$ 0.133). 
Table 4. Risk of different pregnancy outcomes in women with gestational diabetes mellitus according to gestational weight gain.

\begin{tabular}{|c|c|c|c|c|c|c|c|c|}
\hline \multirow[t]{2}{*}{ Outcome } & \multicolumn{4}{|c|}{$\begin{array}{c}\text { Unadjusted OR } \\
\text { Unadjusted CI 95\% }\end{array}$} & \multicolumn{4}{|c|}{$\begin{array}{c}\text { Adjusted OR }{ }^{*} \\
\text { Adjusted CI 95\% }\end{array}$} \\
\hline & iGWG & aGWG & eGWG & Overall $p$ & iGWG & aGWG & eGWG & Overall $p$ \\
\hline \multirow{2}{*}{$\begin{array}{l}\text { Pregnancy-induced } \\
\text { hypertension }\end{array}$} & 0.604 & 1 & 1.949 & \multirow[t]{2}{*}{$<0.001$} & 0.655 & 1 & 1.357 & \multirow[b]{2}{*}{0.028} \\
\hline & $0.397-0.920$ & 1 & $1.282-2.963$ & & $0.396-1.085$ & 1 & $0.818-2.253$ & \\
\hline \multirow{2}{*}{ Preeclampsia } & 0.785 & 1 & 4.095 & \multirow{2}{*}{0.054} & 1.008 & 1 & 6.519 & \multirow{2}{*}{$<0.050$} \\
\hline & $0.109-5.658$ & 1 & $0.832-20.161$ & & $0.077-13.163$ & 1 & $0.746-56.939$ & \\
\hline \multirow{2}{*}{ Insulin treatment } & 0.955 & 1 & 1.219 & \multirow[t]{2}{*}{0.068} & - & 1 & - & \multirow{2}{*}{ ns } \\
\hline & $\begin{array}{c}0.805-1.134 \\
\mathbf{0 . 8 1 2}\end{array}$ & $\begin{array}{l}1 \\
1\end{array}$ & $\begin{array}{c}0.976-1.523 \\
\mathbf{1 . 8 9 8}\end{array}$ & & 0.715 & $\begin{array}{l}1 \\
1\end{array}$ & 1.641 & \\
\hline Cesarean delivery & $0.660-0.999$ & 1 & $1.488-2.419$ & $<0.001$ & $0.556-0.920$ & 1 & $1.225-2.197$ & $<0.001$ \\
\hline \multirow{2}{*}{ Fetal scalp blood $\mathrm{pH}<7.25$} & 0.777 & 1 & 1.367 & \multirow[t]{2}{*}{0.081} & - & 1 & - & \multirow{2}{*}{ ns } \\
\hline & $0.492-1.225$ & 1 & $0.810-2.306$ & & - & 1 & - & \\
\hline \multirow{2}{*}{ Preterm birth } & 2.029 & 1 & 0.689 & \multirow[t]{2}{*}{$<0.001$} & _- & 1 & - & \multirow{2}{*}{ ns } \\
\hline & $1.546-2.832$ & 1 & $0.424-1.121$ & & - & 1 & - & \\
\hline \multirow{2}{*}{ Apgar at $5 \min <7$} & 1.647 & 1 & 1.182 & \multirow[t]{2}{*}{0.739} & 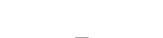 & 1 & _ & \multirow{2}{*}{ ns } \\
\hline & $0.436-6.226$ & 1 & $0.197-7.097$ & & - & 1 & - & \\
\hline \multirow{2}{*}{ Arterial $\mathrm{pH}<7.1$} & 1.138 & 1 & 2.000 & \multirow[t]{2}{*}{0.038} & - & 1 & & \multirow[b]{2}{*}{ ns } \\
\hline & $0.672-1.927$ & 1 & $1.113-3.595$ & & - & 1 & - & \\
\hline Ohctotric troum & 0.793 & 1 & 0.949 & 0.698 & & 1 & & $\mathrm{me}$ \\
\hline Obstetric trauma & $0.453-1.389$ & 1 & $0.466-1.936$ & & - & 1 & - & ns \\
\hline & 0.575 & 1 & 2.952 & $<0.001$ & 0.569 & 1 & 2.003 & -0001 \\
\hline LGA newborn & $0.425-0.777$ & 1 & $2.200-3.962$ & & $0.400-0.810$ & 1 & $1.397-2.871$ & $<0.001$ \\
\hline Mosmomi $1>000$ & 0.412 & 1 & 2.893 & $<0.001$ & 0.461 & 1 & 1.822 & \\
\hline Macrosomia $(\geq 4000 \mathrm{~g})$ & $0.265-0.640$ & 1 & $1.983-4.220$ & & $0.282-0.752$ & 1 & $1.152-2.881$ & $<0.001$ \\
\hline crA nombor & 1.289 & 1 & 0.608 & 0.001 & 1.228 & 1 & 0.515 & 0007 \\
\hline SGA newborn & $0.947-1.706$ & 1 & $0.392-0.943$ & & $0.893-1.689$ & 1 & $0.310-0.855$ & 0.002 \\
\hline & 0.951 & 1 & 1.076 & 0.932 & & 1 & & \\
\hline Neonatal hypoglycemia & $0.547-1.656$ & 1 & $0.534-2.168$ & & - & 1 & - & ns \\
\hline Jaundice requiring & 1.579 & 1 & 1.024 & 0.041 & 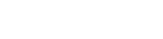 & 1 & 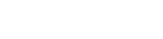 & $n c$ \\
\hline treatment & $1.052-2.369$ & 1 & $0.583-1.800$ & & - & 1 & - & ns \\
\hline Respiratory distress & 2.558 & 1 & 1.086 & 0.001 & & 1 & & $m$ \\
\hline requiring treatment & $1.472-4.447$ & 1 & $0.489-2.413$ & & - & 1 & - & ns \\
\hline No & 2.529 & 1 & odd & 0.177 & 4.557 & 1 & odd & 0120 \\
\hline Neonatal hypocalcemia & $0.952-6.720$ & 1 & coefficient & & $1.037-20.003$ & 1 & coefficient & 0.133 \\
\hline Neonatal polycythemia & 0.904 & 1 & 1.310 & 0665 & - & 1 & _- & ns \\
\hline & $0.433-1.886$ & 1 & $0.548-3.132$ & 0.665 & - & 1 & & ns \\
\hline Perinatal mortality & $\begin{array}{c}1.213 \\
0364-4039\end{array}$ & 1 & $\begin{array}{c}0.437 \\
0.49-3917\end{array}$ & 0.624 & - & 1 & - & ns \\
\hline
\end{tabular}

OR (odds ratio), CI (confidence interval), iGWG (insufficient gestational weight gain), aGWG (adequate gestational weight gain), eGWG (excessive gestational weight gain), LGA (large-for-gestational age), SGA (small-for-gestational age). Logistic regression analysis was used to calculate ORs. * See methods for variables used for adjustment. ORs significantly different from the reference category are marked in bold, - is indicated when IOM is not included in the last step and OR not available. 
In addition to weight gain itself, women in the different categories of gestational weight gain according to IOM differed in 13 out of 20 characteristics.

\section{Discussion}

The present study in a large cohort of women with GDM and satisfactory overall pregnancy outcomes has shown that GWG was very frequently outside IOM recommendations and GWG, in turn, was associated with PIH, preeclampsia, cesarean delivery, LGA, macrosomia and SGA with eGWG essentially linked with higher risks and iGWG with lower ones.

\subsection{Prevalence and of Inadequate GWG}

The distribution of GWG according to IOM in this cohort (50.3\% insufficient, 31.6\% adequate, $18.1 \%$ excessive) is far away from IOM recommendations. The rate of eGWG is similar to that in the study of Barquiel et al., also in Spain (14.7\%) [19]—iGWG was not reported in this article [19]. In a meta-analysis of more than 80,000 patients with GDM, rates of inadequate GWG were also very high (30\% insufficient, $34 \%$ adequate and $37 \%$ excessive) [13] and this was also the case in a recent article on this subject [31]. However, the GWG distribution in this study is clearly shifted towards iGWG whereas in other publications on this subject, the percentage of insufficient and excessive GWG is more balanced. We partially attribute this difference to the fact that, in the center, the glycemic control goals $(90 \mathrm{mg} / \mathrm{dL}$ basal/preprandial, $<120 \mathrm{mg} / \mathrm{dL} 1 \mathrm{~h}$ postprandial) are tighter than usual $(95 \mathrm{mg} / \mathrm{dL}$ basal/preprandial, $<140 \mathrm{mg} / \mathrm{dL} 1 \mathrm{~h}$ postprandial). This may facilitate that in order to avoid or delay insulin treatment, there is a larger caloric restriction and/or increased exercise. However, we think that the fundamental factor is that in the population herein reported, the percentage of prepregnancy overweight/obesity is much lower than in the aforementioned meta-analysis $(34.2 \%$ vs. $68 \%)$ and we have also seen that this is associated to less eGWG.

\subsection{Variables Independently Associated with Inadequate GWG}

The study has identified seven independent variables for inadequate GWG, namely non-Caucasian ethnicity, unfavorable obstetric history, maternal height, prepregnancy BMI category, smoking habit, gestational age at delivery and length of follow-up for GDM.

For iGWG, independent variables were unfavorable obstetric history, height, prepregnancy overweight /obesity, active smoking/quitting smoking during pregnancy, gestational age at delivery and length of follow-up, all of them negatively associated with the exception of length of follow-up. For eGWG, independent variables were non-Caucasian ethnicity, prepregnancy overweight /obesity, active smoking/quitting smoking during pregnancy; maternal height and length of follow-up displayed borderline significance.

\subsubsection{Ethnicity}

The association of ethnicity with eGWG herein described is in line with information in the literature of inadequate GWG being different according to ethnicity both in the general obstetric population [32,33] and in women with GDM [31].

\subsubsection{Maternal Anthropometry}

The observation that height is associated with GWG is in line with the report of Straube et al., describing that for a given maternal BMI, weight gain during pregnancy increased with maternal height [34], and also with the more recent report of Khanolkar et al., describing that maternal height increases with the category of GWG (insufficient < adequate < excessive) [35].

Our observation of a negative association between prepregnancy overweight/obesity and iGWG and a positive one with eGWG is broadly in line with current information both in the general pregnant population and in women with GDM. In the general pregnant population, Lindberg et al. described 
that underweight was associated with a higher risk of iGWG, and overweight, and obesity class I and II with eGWG [36]. In women with GDM, Wong et al. also have described that, in relation to women gaining within recommendations, those with eGWG had a higher prepregnancy BMI (28.4 vs. $25.0 \mathrm{~kg} / \mathrm{m}^{2}$ ), whereas those gaining less than recommended displayed no differences [31].

\subsubsection{Unfavorable Obstetric History}

We attribute the lower odds of insufficient GWG (OR 0.520, CI 95\% 0.387-0.700) with unfavorable obstetric history to the fact that the latter was usually due to a macrosomic baby in a prior pregnancy and eGWG is a well-known risk factor for this condition [35]. We speculate that women with a prior macrosomic baby had eGWG in a prior pregnancy and repeated the pattern of GWG in current pregnancy.

\subsubsection{Smoking}

It is well-known that nicotine increases energy expenditure, and may reduce appetite, so that smokers tend to have lower body weight and at the same time smoking cessation is commonly followed by weight gain both outside [37] and during pregnancy [36,38]. In the same line, in the current study women beginning pregnancy as smokers and quitting during pregnancy had a higher odds of eGWG (OR 1.614, 1.121-2.325) and a lower odds of iGWG (OR 0.668, 0.490-0.910). However, the observation that women who continued smoking during pregnancy also had a similar pattern of GWG can seem counterintuitive at first glance. Our interpretation is that women who continue to smoke during pregnancy reduce the consumption of cigarettes to a similar or higher extent than those who quit. In the last 10 years, where specific information on number of cigarettes consumed has been collected $(\mathrm{N}=234)$, women who continued to smoke during pregnancy reduced the number of cigarettes in the same range than those who stopped (from 16.9 to 5.9 vs. 8 to 0 , data not shown). Thus, the reduction in cigarettes per day would be similar in women who continued smoking during pregnancy and those who quitted, and similar patterns of GWG could be expected. Other studies in the general obstetric population have associated active smoking either with insufficient GWG [36] or smoking (unclear definition) with a twofold risk of excessive GWG [9].

\subsubsection{Gestational Age at Delivery and Length of Follow-up}

We observed that earlier gestational age at delivery and longer follow-up was associated with a higher frequency of iGWG. The interpretation of higher odds of iGWG with shorter duration of pregnancy is straightforward. As to length follow-up, although we do not have specific information on weight gain before and after initiation of specific follow-up for GDM, we attribute overall results of GWG according to IOM to the impact of the intervention for GDM. The diet initially prescribed is normocaloric but it is modified afterwards (by healthcare providers and by pregnant women themselves) to achieve the metabolic goals [39]. This is in line with the observations of Berglund et al., where women with GDM had a lower total GWG versus women with normal glucose tolerance at the expense of a lower GWG after diagnosis [18], and with those of Hillier et al., who recently reported that obese women with GDM had less eGWG when diagnosed after early screening than at 24-28 weeks (35 vs. 59\%) [40]. The current report establishes this fact in a much larger population.

As to independent predictors of GWG, only length of specific follow-up for GDM can be considered as modifiable during pregnancy, in contrast with smoking habit and gestational age at delivery. Follow-up for GDM is required for the treatment of the condition. In addition, taking into account the essentially satisfactory pregnancy outcomes with iGWG, poorer outcomes with eGWG and the association of length of follow-up with both (borderline with eGWG), we conclude that follow-up for GDM likely has an impact on outcomes through GWG. 


\subsection{Inadequate GWG and Pregnancy Outcomes}

\subsubsection{PIH and Preeclampsia}

With regard to pregnancy outcomes, in the adjusted analysis, hypertensive disorders (both PIH and preeclampsia) were associated with GWG categories even when, individually, iGWG and eGWG were not significantly different from aGWG. The direction of the association was towards a higher risk with eGWG and a lower risk with iGWG. The magnitude of the association was nominally larger for preeclampsia than for PIH (i.e., the aOR and 95\%CI for eGWG was $6.519,0.746-56.939$ for preeclampsia vs. $1.357,0.818-2.253$ for PIH).

These observations are in line with data from previous investigations. In the general obstetric population Fortner et al. reported that women with eGWG had a $\simeq 3$-fold increased risk for hypertension and a $\simeq 4$-fold increased risk for preeclampsia, compared with aGWG [41]. On the other side, there is a reduced risk of hypertensive disorders in association with iGWG [42]. Among women with GDM, the abovementioned meta-analysis also observed a significant association with eGWG with hypertensive disorders of pregnancy (OR 1.65) but no association with iGWG [13]. Interestingly, GWG is positively associated with concurrent blood pressure in all gestational periods [41] and some authors have only observed an association in the third trimester (i.e., Gaillard for preeclampsia [9] or Gonzalez et al. for PIH [43]). Thus, GWG from the diagnosis of GDM onwards could play a relevant a role in the risk of $\mathrm{PIH}$ and preeclampsia and we have shown that the length of specific follow-up for GDM is negatively associated with GWG supporting a beneficial role of GDM care.

\subsubsection{Cesarean Delivery}

We also have observed an association of GWG with cesarean delivery: the risk was higher in women with eGWG (aOR 1.641, $95 \%$ CI 1.225-2.197) and lower in those with iGWG (0.715, 0.556-0.920). This is in agreement with information in the general obstetric population [44] and partially with data in women with GDM where the negative association of iGWG with cesarean delivery did not reach significance [13]. Since GWG in second [45] and third trimesters [46] has been related with cesarean delivery, we consider that the relationships described in this study are partially attributable to GWG taking place after GDM diagnosis and affected by its management.

\subsubsection{LGA, Macrosomia and SGA}

In this series, eGWG was associated with a higher odds of LGA (aOR 2.003, 95\% CI 1.397-2.871) and macrosomia (aOR 1.822,95\% CI 1.152-2.881), results that are perfectly in line with those observed in meta-analyses both in the general obstetric population (respective ORs of 1.85 and 1.95) [47] and in women with GDM (respective RRs of 2.08 and 1.87) [13]. As to SGA newborns, eGWG was associated with less risk (aOR $0.515,95 \%$ CI $0.310-0.855$ ), and iGWG was not significantly different from the reference category (aOR 1.228, 95\% CI 0.893-1.689). This is also in line with meta-analysis results in women with GDM where summary figures for individual categories of IGWG (RR 1.40) and eGWG (RR 0.57) were not significantly different from aGWG [13]. However, in the general obstetric population, individual IOM categories display similar risks in terms of SGA and are significantly different from reference (OR 1.53 for iGWG and 0.66 for eGWG) [47]. Thus, the lack of significance in women with GDM is likely attributable to insufficient statistical power. The relationship between GWG and birthweight-related outcomes is present throughout pregnancy [9,48], so we also consider that observed associations of GWG with these outcomes are partly attributable to weight gain after GDM diagnosis.

We have not observed significant associations of GWG with the additional 12 outcomes addressed in the current investigation. Viecelli et al. did not show an association between GWG with either drug treatment or preterm birth. They did not address the other 10 variables [13]. Overall, GWG was not associated with neonatal hypocalcemia, but the category of iGWG displayed a positive association (OR 4.557, 95\% CI 1.037-20.003). The association could be mediated through reduced birthweight [49] and requires confirmation. 


\subsection{Is iGWG Satisfactory in Women with GDM?}

In relation to pregnancy outcomes, eGWG is associated with higher risks, and iGWG with a more favorable pattern. In fact, different authors have suggested that definition of adequate GWG should use more stringent limits in women with GDM [31,50], with approaches such as subtracting $2 \mathrm{~kg}$ to the limits indicated by IOM [31] or deriving specific limits using ROC curves [51].

iGWG during pregnancy also raises the issue of ketogenesis, known to be associated with neurocognitive outcomes in the offspring [52]. It is usually recommended to monitor ketones in women with GDM displaying overt hyperglycemia and/or weight loss during follow-up even when this has not been formally tested to improve fetal outcomes [53]. In fact, it has been our practice for decades [54] to recommend urinary ketone monitoring in women with GDM and not only before breakfast [55] in order to identify its presence and introduce modifications for its prevention. Thus, we consider that women in this series, have not displayed significant amounts of urinary ketones during follow-up for GDM or at least, not for long periods.

The observed GWG distribution can be viewed as a good outcome according to the observed association with pregnancy outcomes. However, a recent study in a general obstetric population in Hong Kong has reported that inadequate GWG is associated with adiposity, hypertension and insulin resistance in offspring at 7 years of age, independently of factors such as gestational hyperglycemia or birthweight [56]. The association is present both for excessive and insufficient GWG but more marked for eGWG and especially for extreme values. The relationship of iGWG with long-term adiposity and insulin resistance would be akin to situations such as maternal treatment with metformin $[57,58]$ or prevention of GDM through lifestyle intervention [59]. Should these observations be confirmed in women with GDM, the distribution of GWG herein described should be viewed as less satisfactory.

The results herein presented confirm data in the literature and also include novel observations among predictors of GWG (maternal height, active smoking and length of follow-up) and also among its association with pregnancy outcomes (iGWG associated with a lower rate of cesarean delivery).

The strength of our retrospective study is the large sample size of the cohort. We provide data on more than two thousand women with GDM and have performed a comprehensive analysis of the predictors of inadequate GWG according to IOM 2009 and its association with pregnancy outcomes. The study has several limitations. This is an observational, retrospective, single-center study, hence selection and information bias cannot be ruled out. A second limitation is that only information on total GWG is available and we have not been able to address weight gain after initiation of specific follow-up for GDM. Another limitation is that information on preeclampsia is only available in a reduced subset of women.

\section{Conclusions}

In summary, in this cohort of women with GDM, inadequate GWG was very common at the expense of iGWG; length of clinical follow-up for GDM was the only independent variable that is modifiable during pregnancy, after GDM diagnosis. The associations of GWG with pregnancy outcomes were essentially favorable for iGWG and unfavorable for eGWG.

Author Contributions: Conceptualization, X.X., J.L. and R.C.; formal analysis, X.X., J.L. and R.C.; investigation, X.X., J.L., I.P., A.L., M.J.M., A.G.-P., J.M.A., G.G., and R.C.; data curation, X.X., J.L., I.P., A.L., M.J.M., A.G.-P., J.M.A., G.G., and R.C.; writing—original draft preparation, X.X., J.L. and R.C.; writing—review and editing, X.X., J.L., I.P., A.L., M.J.M., A.G.-P., J.M.A., G.G., and R.C.; supervision, R.C. All authors have read and agreed to the published version of the manuscript.

Funding: This research received no external funding.

Conflicts of Interest: The authors declare no conflict of interest. 
Appendix A

Table A1. Recommendations of GWG according to IOM 2009 [60]:

\begin{tabular}{lcc}
\hline \multirow{2}{*}{ Pre-Pregnancy BMI Category $\left(\mathbf{k g} / \mathbf{m}^{2}\right)$} & \multicolumn{2}{c}{ Recommended Range of GWG During Pregnancy $(\mathbf{k g})$} \\
\cline { 2 - 3 } & Singleton Pregnancy & Multiple Pregnancy \\
\hline Underweight $(\mathrm{BMI}<18.5)$ & $12.5-18.0$ & \\
\hline Normal weight $(\mathrm{BMI}=18.5-24.9)$ & $11.5-16.0$ & $16.8-24.5$ \\
\hline Overweight $(\mathrm{BMI}=25.0-29.9)$ & $7.0-11.5$ & $14.1-22.7$ \\
\hline Obesity $(\mathrm{BMI} \geq 30)$ & $5.0-9.0$ & $11.3-19.1$ \\
\hline
\end{tabular}

GWG: gestational weight gain, IOM: Institute of Medicine, BMI: body mass index.

\section{Appendix B}

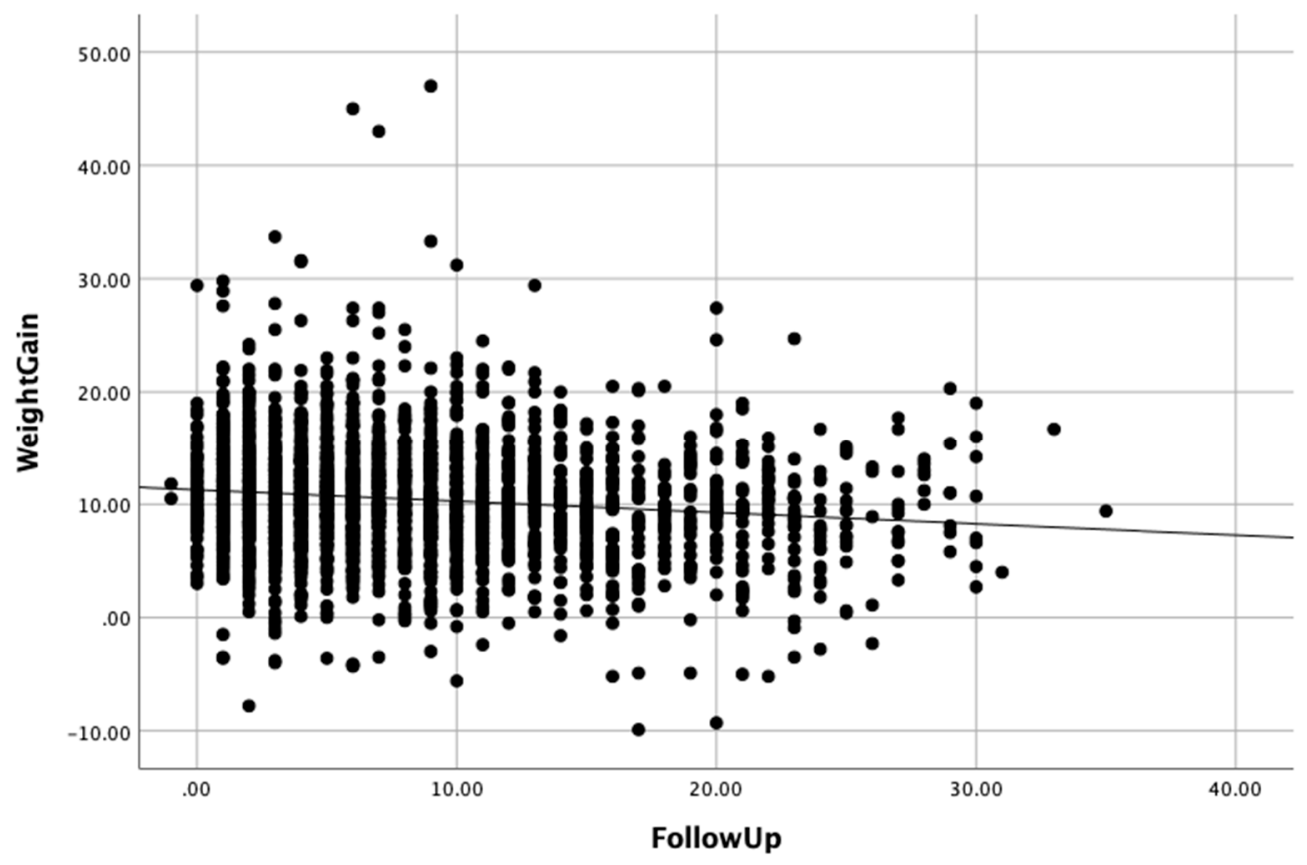

Figure A1. Scatterplot of gestational weight gain (in kg) vs. length of follow-up (in weeks).

\section{References}

1. ADA. 2. Classification and Diagnosis of Diabetes: Standards of Medical Care in Diabetes 2020. Diabetes Care 2020, 43, 14-31. [CrossRef] [PubMed]

2. Albareda, M.; Caballero, A.; Badell, G.; Piquer, S.; Ortiz, A.; De Leiva, A.; Corcoy, R. Diabetes and abnormal glucose tolerance in women with previous gestational diabetes. Diabetes Care 2003, 26, 1199-1205. [CrossRef]

3. Wendland, E.M.; Torloni, M.R.; Falavigna, M.; Trujillo, J.; Dode, M.A.; Campos, M.A.; Duncan, B.B.; Schmidt, M.I. Gestational diabetes and pregnancy outcomes-A systematic review of the World Health Organization (WHO) and the International Association of Diabetes in Pregnancy Study Groups (IADPSG) diagnostic criteria. BMC Pregnancy Childbirth 2012, 12, 23. [CrossRef] [PubMed]

4. Bellamy, L.; Casas, J.; Hingorani, A.D.; Williams, D. Type 2 diabetes mellitus after gestational diabetes: A systematic review and meta-analysis. Lancet 2009, 373, 1773-1779. [CrossRef]

5. Sendag, F.; Terek, M.C.; Itil, I.M.; Oztekin, K.; Bilgin, O. Maternal and perinatal outcomes in women with gestational diabetes mellitus as compared to nondiabetic controls. J. Reprod. Med. 2001, 46, 1057-1062.

6. Abenhaim, H.A.; Kinch, R.A.; Morin, L.; Benjamin, A.; Usher, R. Effect of prepregnancy body mass index categories on obstetrical and neonatal outcomes. Arch. Gynecol. Obstet. 2007, 275, 39-43. [CrossRef] 
7. Catalano, P.M.; McIntyre, H.D.; Cruickshank, J.K.; McCance, D.R.; Dyer, A.R.; Metzger, B.E.; Lowe, L.P.; Trimble, E.R.; Coustan, D.R.; Hadden, D.R.; et al. The hyperglycemia and adverse pregnancy outcome study: Associations of GDM and obesity with pregnancy outcomes. Diabetes Care 2012, 35, 780-786. [CrossRef] [PubMed]

8. Ricart, W.; López, J.; Mozas, J.; Pericot, A.; Sancho, M.A.; González, N.; Balsells, M.; Luna, R.; Cortázar, A.; Navarro, P.; et al. Body mass index has a greater impact on pregnancy outcomes than gestational hyperglycaemia. Diabetologia 2005, 48, 1736-1742. [CrossRef] [PubMed]

9. Gaillard, R.; Durmuş, B.; Hofman, A.; MacKenbach, J.P.; Steegers, E.A.P.; Jaddoe, V.W.V. Risk factors and outcomes of maternal obesity and excessive weight gain during pregnancy. Obesity 2013, 21, 1046-1055. [CrossRef]

10. Haugen, M.; Brantsæter, A.L.; Winkvist, A.; Lissner, L.; Alexander, J.; Oftedal, B. Associations of pre-pregnancy body mass index and gestational weight gain with pregnancy outcome and postpartum weight retention: A prospective observational cohort study. BMC Pregnancy Childbirth 2014, 201. [CrossRef]

11. Viswanathan, M.; Siega-Riz, A.M.; Moos, M.K.; Deierlein, A.; Mumford, S.; Knaack, J.; Thieda, P.; Lux, L.J.; Lohr, K.N. Outcomes of maternal weight gain. Evid Rep. Technol. Assess. Full. Rep. 2008, 1-223.

12. Siega-Riz, A.M.; Viswanathan, M.; Moos, M.K.; Deierlein, A.; Mumford, S.; Knaack, J.; Thieda, P.; Lux, L.J.; Lohr, K.N. A systematic review of outcomes of maternal weight gain according to the Institute of Medicine recommendations: Birthweight, fetal growth, and postpartum weight retention. Am. J. Obstet. Gynecol. 2009, 201, 339.e1-339.e14. [CrossRef] [PubMed]

13. Viecceli, C.; Remonti, L.R.; Hirakata, V.N.; Mastella, L.S.; Gnielka, V.; Oppermann, M.L.R.; Silveiro, S.P.; Reichelt, A.J. Weight gain adequacy and pregnancy outcomes in gestational diabetes: A meta-analysis. Obes. Rev. 2017, 18, 567-580. [CrossRef] [PubMed]

14. American College of Obstetricians and Gynecologists. Weight gain during pregnancy. Obstet. Gynecol. 2013, 121, 171-173.

15. Stewart, Z.A.; Wallace, E.M.; Allan, C. A Patterns of weight gain in pregnant women with and without gestational diabetes mellitus: An observational study. Aust. N. Z. J. Obstet. Gynaecol. 2012. [CrossRef]

16. Egan, A.M.; Dennedy, M.C.; Al-Ramli, W.; Heerey, A.; Avalos, G.; Dunne, F. ATLANTIC-DIP: Excessive gestational weight gain and pregnancy outcomes in women with gestational or pregestational diabetes mellitus. J. Clin. Endocrinol. Metab. 2014, 99, 212-219. [CrossRef] [PubMed]

17. Barquiel, B.; Herranz, L.; Meneses, D.; Moreno, Ó.; Hillman, N.; Burgos, M.Á.; Bartha, J.L. Optimal Gestational Weight Gain for Women with Gestational Diabetes and Morbid Obesity. Matern. Child. Health J. 2018, 22, 1297-1305. [CrossRef]

18. Berglund, S.K.; García-Valdés, L.; Torres-Espinola, F.J.; Segura, M.T.; Martínez-Zaldívar, C.; Aguilar, M.J.; Agil, A.; Lorente, J.A.; Florido, J.; Padilla, C.; et al. Maternal, fetal and perinatal alterations associated with obesity, overweight and gestational diabetes: An observational cohort study (PREOBE). BMC Public Health 2016, 16, 207. [CrossRef] [PubMed]

19. Barquiel, B.; Herranz, L.; Hillman, N.; Burgos, M.Á.; Grande, C.; Tukia, K.M.; Bartha, J.L.; Pallardo, L.F. $\mathrm{HbA1c}$ and gestational weight gain are factors that influence neonatal outcome in mothers with gestational diabetes. J. Women's Health 2016, 25, 579-585. [CrossRef]

20. Ricart, W.; López, J.; Mozas, J.; Pericot, A.; Sancho, M.A.; González, N.; Balsells, M.; Luna, R.; Cortázar, A.; Navarro, P.; et al. Potential impact of American Diabetes Association (2000) criteria for diagnosis of gestational diabetes mellitus in Spain. Diabetologia 2005, 48, 1135-1141. [CrossRef] [PubMed]

21. Acosta, D.; Balsells, M.; Ballesteros, M.; Bandres, M.O.; Bartha, J.L.; Bellart, J.; Chico, A.I.; Codina, M.; Corcoy, R.; Cortázar, A.; et al. Asistencia a la gestante con diabetes. Guía de práctica clínica actualizada en 2014. Av. Diabetol. 2015, 31, 45-59. [CrossRef]

22. National Institute for Health and Care Excellence. NICE Intrapartum Care: Care of Healthy Women and Their Babies During Childbirth Guidance and Guidelines. 2014. Available online: www.nice.org.uk/guidance/cg190 (accessed on 15 December 2014).

23. American College of Obstetricians and Gynecologists. ACOG Committee Opinion No. 644: The Apgar Score. Obstet. Gynecol. 2015, 126, e52-e55. [CrossRef] [PubMed]

24. Yeh, P.; Emary, K.; Impey, L. The relationship between umbilical cord arterial $\mathrm{pH}$ and serious adverse neonatal outcome: Analysis of 51519 consecutive validated samples. BJOG Int. J. Obstet. Gynaecol. 2012, 119, 824-831. [CrossRef] [PubMed] 
25. Santamaria Lozano, R.; Verdú Martín, L.; Martín Caballero, C.; García López, G. Tablas Españolas de Pesos Neonatales Según Edad Gestacional; Ed. Artes Gráficas Beatulo: Badalona, Spain, 1998; Available online: https//www.menarini.es/aviso-legal/509-salud/areas-terapeuticas/ginecologia/3073-tablas-espanolasde-pesos-neonatales.html (accessed on 15 June 2018).

26. Cornblath, M.; Schwartz, R. Hypoglycemia in the neonate. J. Pediatr. Endocrinol. 1993, 6, 113-129. [CrossRef]

27. Maisels, M.J. Bilirubin: On understanding and influencing its metabolism in the newborn infant. Pediatr. Clin. N. Am. 1972, 19, 447-501. [CrossRef]

28. Edwards, M.O.; Kotecha, S.J.; Kotecha, S. Respiratory Distress of the Term Newborn Infant. Paediatr. Respir. Rev. 2013, 14, 29-37. [CrossRef] [PubMed]

29. Loughead, J.L.; Mimouni, F.; Tsang, R.C. Serum Ionized Calcium Concentrations in Normal Neonates. Am. J. Dis. Child. 1988, 142, 516-518. [CrossRef]

30. Kates, E.H.; Kates, J.S. Anemia and polycythemia in the newborn. Pediatr. Rev. 2007, 28, 33-34. [CrossRef]

31. Wong, T.; Barnes, R.A.; Ross, G.P.; Cheung, N.W.; Flack, J.R. Are the Institute of Medicine weight gain targets applicable in women with gestational diabetes mellitus? Diabetologia 2017, 60, 416-423. [CrossRef]

32. Headen, I.E.; Davis, E.M.; Mujahid, M.S.; Abrams, B. Racial-Ethnic Differences in Pregnancy-Related Weight. Adv. Nutr. 2012, 3, 83-94. [CrossRef]

33. Cheng, H.R.; Walker, L.O.; Brown, A.; Lee, J.Y. Gestational Weight Gain and Perinatal Outcomes of Subgroups of Asian-American Women, Texas, 2009. Women's Health Issues 2015, 25, 303-311. [CrossRef]

34. Straube, S.; Voigt, M.; Briese, V.; Schneider, K.T.M.; Voigt, M. Weight gain in pregnancy according to maternal height and weight. J. Perinat. Med. 2008, 36, 405-412. [CrossRef] [PubMed]

35. Khanolkar, A.R.; Hanley, G.E.; Koupil, I.; Janssen, P.A. 2009 IOM guidelines for gestational weight gain: How well do they predict outcomes across ethnic groups? Ethn. Health 2017, 25, 1-16. [CrossRef]

36. Lindberg, S.; Anderson, C.; Pillai, P.; Tandias, A.; Arndt, B.; Hanrahan, L. Prevalence and predictors of unhealthy weight gain in pregnancy. Wis. Med. J. 2016, 115, 233-237.

37. Chiolero, A.; Faeh, D.; Paccaud, F.; Cornuz, J. Consequences of smoking for body weight, body fat distribution, and insulin resistance. Am. J. Clin. Nutr. 2008, 87, 801-809. [CrossRef]

38. Hulman, A.; Lutsiv, O.; Park, C.K.; Krebs, L.; Beyene, J.; McDonald, S.D. Are women who quit smoking at high risk of excess weight gain throughout pregnancy? BMC Pregnancy Childbirth 2016, 16, 263. [CrossRef] [PubMed]

39. Hagiwara, Y.; Kasai, J.; Nakanishi, S.; Saigusa, Y.; Miyagi, E.; Aoki, S. Should the IADPSG criteria be applied when diagnosing early-onset gestational diabetes? Diabetes Res. Clin. Pract. 2018, 140, 154-161. [CrossRef] [PubMed]

40. Hillier, T.A.; Ogasawara, K.K.; Pedula, K.L.; Vesco, K.K.; Oshiro, C.E.S.; Van Marter, J.L. Timing of Gestational Diabetes Diagnosis by Maternal Obesity Status: Impact on Gestational Weight Gain in a Diverse Population. J. Women's Health 2020, 29, 1-9. [CrossRef]

41. Fortner, R.T.; Pekow, P.; Solomon, C.G.; Markenson, G.; Chasan-Taber, L. Prepregnancy body mass index, gestational weight gain, and risk of hypertensive pregnancy among Latina women. Am. J. Obstet. Gynecol. 2009, 200, 167.e1-167.e7. [CrossRef]

42. Macdonald-Wallis, C.; Tilling, K.; Fraser, A.; Nelson, S.M.; Lawlor, D.A. Gestational weight gain as a risk factor for hypertensive disorders of pregnancy. Am. J. Obstet. Gynecol. 2013, 209, 327.e1-327.e17. [CrossRef]

43. Gonzalez-Ballano, I.; Saviron-Cornudella, R.; Esteban, L.M.; Sanz, G.; Castán, S. Pregestational body mass index, trimester-specific weight gain and total gestational weight gain: How do they influence perinatal outcomes? J. Matern. Neonatal Med. 2019, 1-8. [CrossRef] [PubMed]

44. Xiong, C.; Zhou, A.; Cao, Z.; Zhang, Y.; Qiu, L.; Yao, C.; Wang, Y.; Zhang, B. Association of pre-pregnancy body mass index, gestational weight gain with cesarean section in term deliveries of China. Sci. Rep. 2016, 6, 37168. [CrossRef] [PubMed]

45. Drehmer, M.; Duncan, B.B.; Kac, G.; Schmidt, M.I. Association of Second and Third Trimester Weight Gain in Pregnancy with Maternal and Fetal Outcomes. PLoS ONE 2013, 8. [CrossRef]

46. Harvey, M.W.; Braun, B.; Ertel, K.A.; Pekow, P.S.; Markenson, G.; Chasan-Taber, L. Prepregnancy Body Mass Index, Gestational Weight Gain, and Odds of Cesarean Delivery in Hispanic Women. Obesity 2018, 26, 185-192. [CrossRef] [PubMed] 
47. Goldstein, R.F.; Abell, S.K.; Ranasinha, S.; Misso, M.; Boyle, J.A.; Black, M.H.; Li, N.; Hu, G.; Corrado, F.; Rode, L.; et al. Association of gestational weight gain with maternal and infant outcomes: A systematic review and meta-analysis. JAMA J. Am. Med. Assoc. 2017, 317, 2207-2225. [CrossRef]

48. Kramer, C.K.; Campbell, S.; Retnakaran, R. Gestational diabetes and the risk of cardiovascular disease in women: A systematic review and meta-analysis. Diabetologia 2019, 62, 905-914. [CrossRef]

49. Vuralli, D. Clinical Approach to Hypocalcemia in Newborn Period and Infancy: Who Should Be Treated? Int. J. Pediatr. 2019, 2019, 1-7. [CrossRef] [PubMed]

50. Gou, B.; Guan, H.; Bi, Y.; Ding, B. Gestational diabetes: Weight gain during pregnancy and its relationship to pregnancy outcomes. Chin. Med. J. (Engl.) 2019, 6-11. [CrossRef]

51. Jiang-nan, W.; Wei-rong, G.; Xi-rong, X.; Yi, Z.; Xiao-tian, L.; Chuan-Min, Y. Gestational weight gain targets during the second and third trimesters of pregnancy for women with gestational diabetes mellitus in China. Eur. J. Clin. Nutr. 2018. [CrossRef]

52. Rizzo, T.; Metzger, B.; Burns, W.; Burns, K. Correlations between antepartum maternal metabolism and intelligence of offspring. N. Engl. J. Med. 1991, 325, 911-916. [CrossRef]

53. Metzger, B.E.; Buchanan, T.A.; Coustan, D.R.; De Leiva, A.; Dunger, D.B.; Hadden, D.R.; Hod, M.; Kitzmiller, J.L.; Kjos, S.L.; Oats, J.N.; et al. Summary and recommendations of the Fifth International Workshop-Conference on Gestational Diabetes Mellitus. Diabetes Care 2007, 30. [CrossRef] [PubMed]

54. Corcoy, R.; Codina, M.; Cerqueira, M.J.; Rectoret, G.; Cervera, T.; Cabero, L.; de Leiva, A. Intensive treatment of pregnancy diabetes: Clinical course in 100 patients. Rev. Clin. Esp. 1988, 183, 344-348. [PubMed]

55. Montaner, P.; Ripollés, J.; Pamies, C.; Corcoy, R. Measurement of fasting ketonuria and capillary blood glucose after main meals in women with gestational diabetes mellitus: How well is the metabolic picture captured? J. Obstet. Gynaecol. Res. 2011, 37, 722-728. [CrossRef]

56. Tam, C.H.T.; Ma, R.C.W.; Yuen, L.Y.; Ozaki, R.; Li, A.M.; Hou, Y.; Chan, M.H.M.; Ho, C.S.; Yang, X.; Chan, J.C.N.; et al. The impact of maternal gestational weight gain on cardiometabolic risk factors in children. Diabetologia 2018, 61, 2539-2548. [CrossRef]

57. Jane, L.T.; Aiken, C.E.; Ozanne, S.E. Neonatal, infant, and childhood growth following metformin versus insulin treatment for gestational diabetes: A systematic review and meta-analysis. PLoS Med. 2019, 16, e1002848.

58. Salomaki, H.; Vahatalo, L.H.; Kirsti, L.; Norma, T.J.; Penttinen, A.-M.; Ailanen, L.; Ilyasizadeh, J.; Pesonen, U.; Koulu, M. Prenatal Metformin Exposure in Mice Programs the Metabolic Phenotype of the Offspring during a High Fat Diet at Adulthood. PLoS ONE 2013, 8, e56594. [CrossRef]

59. Grotenfelt, N.E.; Wasenius, N.; Eriksson, J.G.; Huvinen, E.; Stach-lempinen, B.; Koivusalo, S.B.; Rönö, K. Effect of maternal lifestyle intervention on metabolic health and adiposity of offspring: Findings from the Finnish Gestational Diabetes Prevention Study (RADIEL). Diabetes Metab. 2019, 46, 46-53. [CrossRef]

60. Rasmussen, K.; Yaktine, A. Institute of Medicine (US) and National Research Council (US) Committee to Reexamine IOM Pregnancy Weight Guidelines. Weight Gain Pregnancy Reexamining Guidel. 2009. [CrossRef]

Publisher's Note: MDPI stays neutral with regard to jurisdictional claims in published maps and institutional affiliations.

(C) 2020 by the authors. Licensee MDPI, Basel, Switzerland. This article is an open access article distributed under the terms and conditions of the Creative Commons Attribution (CC BY) license (http://creativecommons.org/licenses/by/4.0/). 